Supporting Information For:

\title{
Theoretical Investigations on the Detecting Mechanism of a Typical TNP Fluorescence Sensor and Its Design Strategy
}

Lei Liuab, Bingqing Sunc*, Ran Ding ${ }^{\mathrm{c}}$, Yueyuan $\mathrm{Mao}^{\mathrm{c}}$

a College of Chemical and Materials Engineering, Anhui Science and Technology University. Fengyang 233100, China

b State Key Laboratory of Molecular Reaction Dynamics, Dalian Institute of Chemical Physics, Chinese Academy of Sciences, Dalian, 116000, China

c College of Resource and Environment, Anhui Science and Technology University. Fengyang 233100, China

Corresponding Author: Bingqing Sun, Email: sunbq@ahstu.edu.cn

Contents

Figure S1, S2, Table S1

Figure S3, S4

Table S2, S3, S4
Page Number

S2

S3

S4 

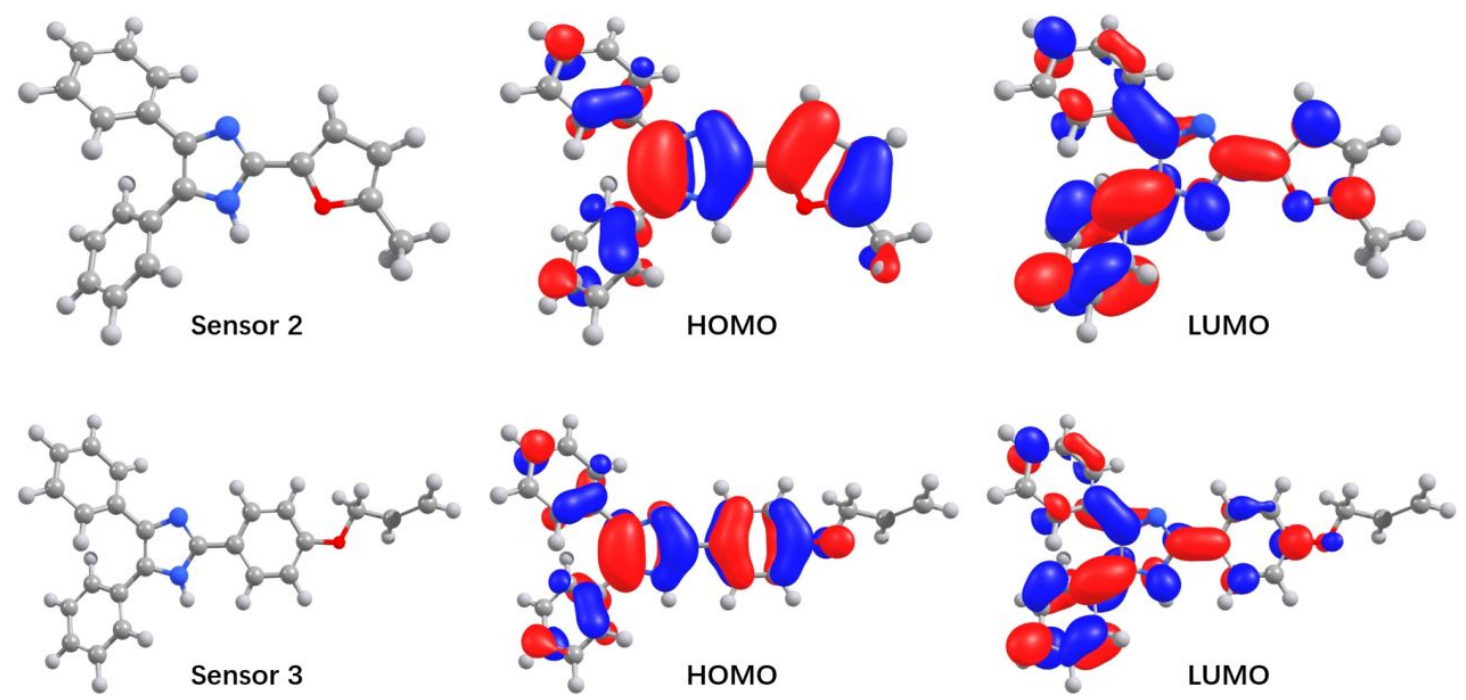

Figure S1. Geometries of sensor 2, sensor 3 and the molecular orbitals involved in their excitation processes.

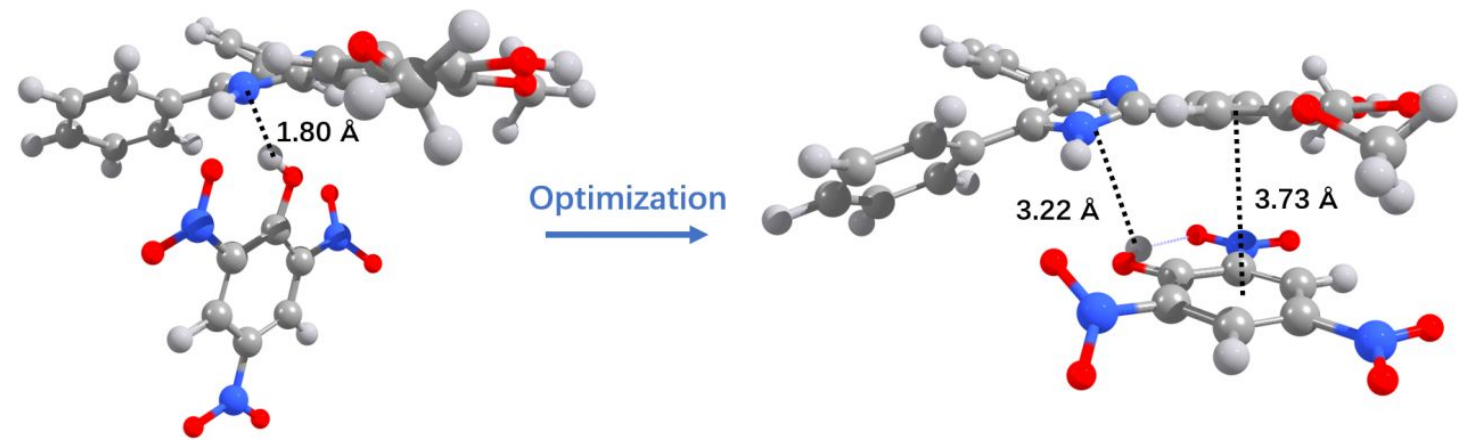

Figure S2. The starting geometry and local minimum of the hydrogen bonding model between sensor and TNP (S-TNP-A).

Table S1. Gibbs free energies and Boltzmann distributions of the three binding model.

\begin{tabular}{ccc}
\hline & Gibbs Free Energy & Distribution \\
\hline S-TNP-A & $11.0 \mathrm{~kJ} / \mathrm{mol}$ & $98.8 \%$ \\
Sensor-TNP & $0 \mathrm{~kJ} / \mathrm{mol}$ & $1.2 \%$ \\
\hline
\end{tabular}




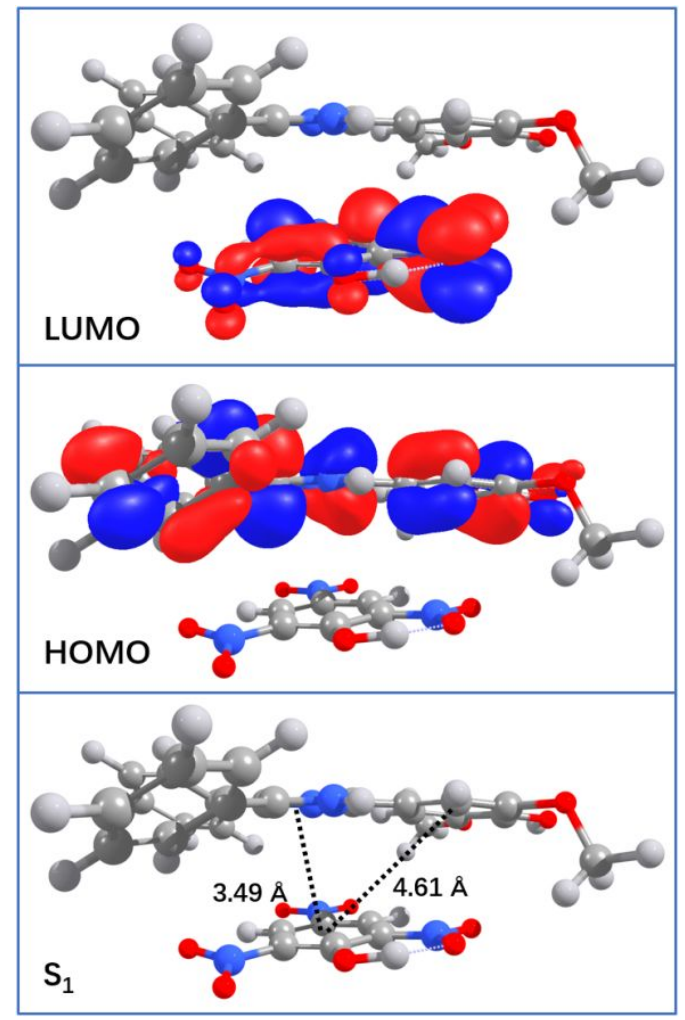

Figure S3. The geometry of the Sensor-TNP in $\mathrm{S}_{1}$ state and the molecular orbitals related.

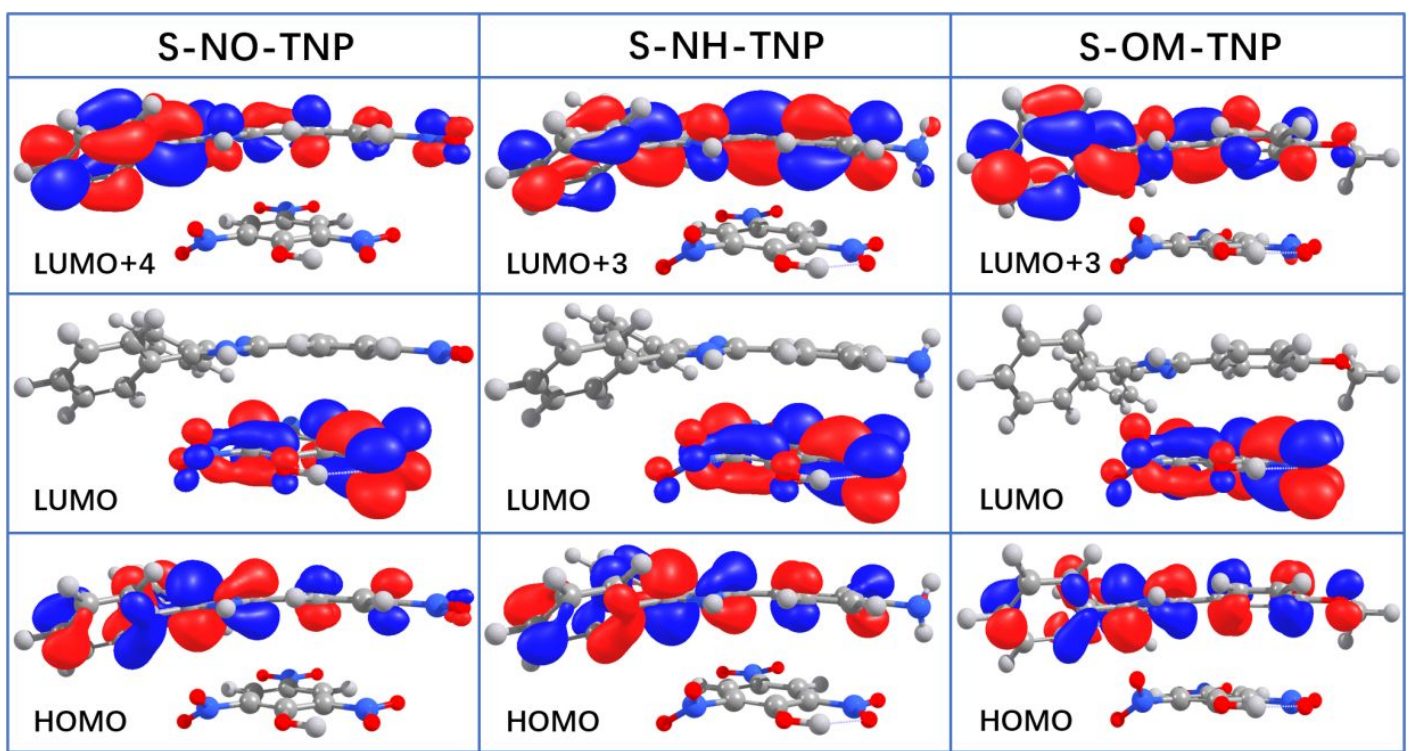

Figure S4. Molecular orbitals involved in the photo excitation process of the analyte-sensor binding complex.

Excitation processes of the three complexes are studied and the calculated data are shown in Table S3. The S-NO-TNP is excited to $\mathrm{S}_{11}$ state which has the largest oscillator strength $(0.2146)$. 151(HOMO) $\rightarrow 155$ (LUMO+4) transition is involved and related orbitals are plotted in Figure S4. Both orbitals distribute on the sensor which means the $S_{11}$ state is a local excited state. The $\mathrm{S}_{1}$ state, by contrast, is an electron transfer state. The LUMO mainly distributes on the TNP sensor, which means the electron transfers from the sensor to the TNP molecule 
during the relaxation process. For the cases of S-OM-TNP and S-NH-TNP, the excitation and relaxation processes are very similar and is not discussed here. It is observed that the photo-physics for all the three complexes is similar to the Sensor-TNP, which means the three sensor can all be applied in the sensing of TNP.

Table S2. Excitation energies of various sensors calculated at CAM-B3LYP/6-31+g(d,p) theory level.

\begin{tabular}{cccc}
\hline & \multicolumn{1}{c}{ Contribution } & Energy & $\mathrm{f}$ \\
\hline $\mathrm{S}_{0} \rightarrow \mathrm{S}_{1}$ & $79(\mathrm{H}) \rightarrow 80(\mathrm{~L}) \begin{array}{c}\text { Sensor2 } \\
(87 \%) \\
\text { Sensor3 }\end{array}$ & $300 \mathrm{~nm}$ & 0.7110 \\
$\mathrm{~S}_{0} \rightarrow \mathrm{S}_{1}$ & $93(\mathrm{H}) \rightarrow 94(\mathrm{~L}) \begin{array}{c}(92 \%) \\
\mathbf{S}-\mathbf{N O}\end{array}$ & $296 \mathrm{~nm}$ & 0.7153 \\
$\mathrm{~S}_{0} \rightarrow \mathrm{S}_{1}$ & $84(\mathrm{H}) \rightarrow 85(\mathrm{~L})\left(\begin{array}{c}(90 \%) \\
\mathbf{S}-\mathbf{O M}\end{array}\right.$ & $320 \mathrm{~nm}$ & 1.0541 \\
$\mathrm{~S}_{0} \rightarrow \mathrm{S}_{1}$ & $86(\mathrm{H}) \rightarrow 87(\mathrm{~L})\left(\begin{array}{c}(90 \%) \\
\mathbf{S}-\mathbf{N H}\end{array}\right.$ & $296 \mathrm{~nm}$ & 0.6709 \\
$\mathrm{~S}_{0} \rightarrow \mathrm{S}_{1}$ & $82(\mathrm{H}) \rightarrow 83(\mathrm{~L})\left(\begin{array}{c}(9 \%) \\
\mathbf{S}-\mathbf{N C 2}\end{array}\right.$ & $294 \mathrm{~nm}$ & 0.6693 \\
$\mathrm{~S}_{0} \rightarrow \mathrm{S}_{1}$ & $98(\mathrm{H}) \rightarrow 99(\mathrm{~L})(92 \%)$ & $295 \mathrm{~nm}$ & 0.7350 \\
\hline
\end{tabular}

Table S3. Excitation energies of various sensor-TNP binding complexes calculated at CAM-B3LYP/6-31+g(d,p) theory level.

\begin{tabular}{|c|c|c|c|}
\hline & Contribution & Energy & $\mathrm{f}$ \\
\hline \multicolumn{4}{|c|}{ Sensor2 } \\
\hline $\mathrm{S}_{0} \rightarrow \mathrm{S}_{1}$ & $137(\mathrm{H}) \rightarrow 138(\mathrm{~L})(95 \%)$ & $543 \mathrm{~nm}$ & 0.0187 \\
\hline $\mathrm{S}_{0} \rightarrow \mathrm{S}_{7}$ & $137 \rightarrow 141(58 \%)$ & $302 \mathrm{~nm}$ & 0.2769 \\
\hline \multicolumn{4}{|c|}{ Sensor3 } \\
\hline $\mathrm{S}_{0} \rightarrow \mathrm{S}_{1}$ & $151(\mathrm{H}) \rightarrow 152(\mathrm{~L})(90 \%)$ & $516 \mathrm{~nm}$ & 0.0068 \\
\hline \multicolumn{3}{|c|}{ S-NO-TNP } & 0.5452 \\
\hline $\mathrm{S}_{0} \rightarrow \mathrm{S}_{1}$ & $147(\mathrm{H}) \rightarrow 148(\mathrm{~L})(87 \%)$ & $448 \mathrm{~nm}$ & 0.0014 \\
\hline \multicolumn{4}{|c|}{ S-OM-TNP } \\
\hline $\mathrm{S}_{0} \rightarrow \mathrm{S}_{1}$ & $144(\mathrm{H}) \rightarrow 145(\mathrm{~L})(94 \%)$ & $522 \mathrm{~nm}$ & 0.0067 \\
\hline $\mathrm{S}_{0} \rightarrow \mathrm{S}_{9}$ & $144 \rightarrow 148(72 \%)$ & $297 \mathrm{~nm}$ & 0.4890 \\
\hline \multicolumn{4}{|c|}{ S-NH-TNP } \\
\hline $\mathrm{S}_{0} \rightarrow \mathrm{S}_{1}$ & $140(\mathrm{H}) \rightarrow 141(\mathrm{~L})(92 \%)$ & $573 \mathrm{~nm}$ & 0.0085 \\
\hline $\mathrm{S}_{0} \rightarrow \mathrm{S}_{9}$ & $140 \rightarrow 144(60 \%)$ & $303 \mathrm{~nm}$ & 0.3026 \\
\hline $\begin{array}{l}\mathrm{S}_{0} \rightarrow \mathrm{S}_{1} \\
\mathrm{~S}_{0} \rightarrow \mathrm{S}_{12}\end{array}$ & $\begin{aligned} & \text { S-NC2-TNP } \\
& 156(\mathrm{H}) \rightarrow 157(\mathrm{~L})(98 \%) \\
& 156 \rightarrow 160(50 \%)\end{aligned}$ & $\begin{array}{l}528 \mathrm{~nm} \\
299 \mathrm{~nm}\end{array}$ & $\begin{array}{l}0.0131 \\
0.2032\end{array}$ \\
\hline
\end{tabular}

Table S4. Equilibrium constants for the formation of Sensor-TNP and sensor-NB complexes.

\begin{tabular}{|c|c|c|}
\hline & Gibbs Free Energy (a.u.) & Equilibrium Constant \\
\hline NB & -436.514312 & - \\
\hline TNP & -920.608249 & - \\
\hline Sensor & -1222.836590 & - \\
\hline
\end{tabular}




\begin{tabular}{|c|c|c|}
\hline Sensor-NB & -1659.342023 & - \\
\hline Sensor-TNP & -2143.443014 & - \\
\hline$\Delta G_{\text {Sensor }-N B}^{\theta}$ & 0.008879 & $8.27 \times 10^{-5}$ \\
\hline$\Delta G_{\text {Sensor }-T N P}^{\theta}$ & 0.001825 & 0.145 \\
\hline$K_{(\text {Sensor }-N B)}^{\theta}$ & - & - \\
\hline$K_{(\text {Sensor }-T N P)}^{\theta}$ & - & \\
\hline
\end{tabular}

The equilibrium constant is calculated by the following equation:

$$
\begin{gathered}
\Delta G_{m}^{\theta}=G_{m}^{\theta}(\text { Complex })-G_{m}^{\theta}(\text { Sensor })-G_{m}^{\theta}(\text { Analyte }) \\
\Delta G_{m}^{\theta}=-R T \ln K^{\theta}
\end{gathered}
$$

